\title{
RELASI ANTARA EFISIENSI OPERASIONAL DAN PROFITABILITAS
}

\author{
Sri Wahyuni Jamal ${ }^{\mathbf{1}}$ \\ swj579@umkt.ac.id, Universitas Muhammadiyah Kalimantan Timur \\ Fenty Fauziah² \\ ff230@umkt.ac.id, Universitas Muhammadiyah Kalimantan Timur \\ Azhar Latief ${ }^{3}$ \\ al824@umkt.ac.id, Universitas Muhammadiyah Kalimantan Timur \\ M. Najeri Al Syahrin ${ }^{4}$ \\ najeri.syahrin@ulm.ac.id, Universitas Lambung Mangkurat
}

\begin{abstract}
Abstrak
Hubungan antara efisiensi operasional dan profitabilitas tidak dapat diabaikan karena peningkatan profitabilitas diperlukan untuk kelangsungan hidup jangka panjang setiap perusahaan. Efisiensi dapat diukur melalui beberapa rasio keuangan dengan menggunakan working capital turnover dan total asset turnover. Variabel ini dipilih karena dapat membantu para pelaku bisnis dan pemegang saham dalam hal mengevaluasi keadaan keuangan perusahaan pertambangan Batubara di masa lalu, sekarang dan perencanaan laba yang akan diperoleh dimasa yang akan datang. Kemudian untuk profitabilitas menggunakan return on asset. Sampel perusahaan yang digunakan adalah sektor pertambangan Batubara sebanyak 10 perusahaan selama 3 tahun dari 2017-2019. Regresi linear berganda digunakan untuk menggambarkan dinamika perubahan return on asset. Berdasarkan hasil analisis, kami menemukan bahwa baik secara parsial maupun secara simultan working capital turnover dan total asset turnover berpengaruh signifikan terhadap return on asset. Diharapkan pihak perusahaan harus lebih hati-hati dan disiplin dalam hal peminjaman, pengumpulan dan pembelanjaan terhadap aset yang dimilikinya agar dapat memberikan keuntungan yang berkelanjutan bagi perusahaan dan pemegang saham.
\end{abstract}

Kata Kunci: return on asset, total asset turnover, working capital turnover

\section{RELATIONSHIP BETWEEN OPERATIONAL EFFICIENCY AND PROFITABILITY Abstract}

The relationship between operational efficiency and profitability cannot be ignored because increasing profitability is necessary for the long-term survival of any company. Efficiency can be measured through several financial ratios using working capital turnover and total asset turnover. This variable was chosen because it can help business people and shareholders in terms of the financial condition of coal mining companies in the past, present and planning the profits to be obtained in the future. Then for profitability using return on assets. The sample of companies used is the coal mining sector as many as 10 companies for 3 years from 2017-2019. Multiple linear regression is used to describe the dynamics of changes in return on assets. Based on the results of the analysis, we found that either partially or simultaneously working capital turnover and total asset turnover have a significant effect on return on assets. It is expected that the company must be more careful and disciplined in terms of borrowing, collecting and spending on its assets in order to provide sustainable benefits for the company and shareholders.

Keywords: return on asset, total asset turnover, working capital turnover 


\section{PENDAHULUAN}

Ekonomi yang terintegarasi secara global telah menjadi penting untuk kelangsungan hidup jangka panjang dan pertumbuhan bisnis perusahaan. Kegiatan ekonomi, dimana pun bidang kegiatan itu berlangsung, dapat dikarakterisasi tergantung pada luaran, dampaknya dan pemenuhan tujuan yang ditargetkan (Stefan, 2015). Misalnya, produksi pertambangan telah dikaitkan dengan banyak sumber risiko (Jonek-Kowalska, 2019). Beberapa di antaranya bersifat umum dan berlaku pada setiap perusahaan yang beroperasi dalam pasar ekonomi (Bijańska \& Wodarski, 2014). Kelompok utama sumber risiko mencakup kondisi internal terkait dengan sumber daya yang berupa aset berwujud dan tidak berwujud, serta kondisi pasar eksternal yang berhubungan dengan prinsip operasi industri dan aturan ekonomi yang diadopsi (Hofman et al., 2017; Korski et al., 2016; Matyjaszek et al., 2018). Informasi tentang volume, pendapatan dan harga telah mendominasi pelaporan keuangan selama lebih dari seratus tahun (Snigaroff \& Wroblewski, 2021). Faktor utama yang menentukan siklus operasi perusahaan adalah jangka waktu persediaan, waktu tahap produksi dan pembayaran utang. Selain itu, faktor-faktor ini juga menentukan jumlah bersih modal kerja (Çelik et al., 2016).

Besarnya modal kerja yang disediakan oleh perusahaan sangat berkaitan erat dengan sikap manajemen dalam menanggapi trade-off antara profitabilitas dan risiko perusahaan. Hal ini akan menentukan modal kerja optimal yang dibutuhkan oleh perusahaan. Manajer yang berhati-hati akan menerapkan kebijakan pembiayaan modal yang konservatif, sedangkan manajer yang optimis akan cenderung menggunakan kebijakan pendanaan yang agresif (Afza \& Nasir, 2007).

Total asset turnover merupakan rasio aktivitas yang mengukur kemampuan perusahaan untuk mengetahui efektivitas penggunaan aktiva dalam menghasilkan penjualan, mengukur perputaran seluruh aktiva yang dimiliki dan mengukur seberapa besar penjualan yang diperoleh dari setiap aset yang dimiliki perusahan (Qamara et al., 2020). Di sisi lain, analisis profitabilitas diperlukan suatu perusahaan dalam pemenuhan informasi dari laporan keuangan yang dipublikasi, meskipun ada perbedaan kinerja perusahaan di masa lalu dengan kinerja perusahaan di masa depan (Stefan, 2015). Rasio profitabilitas merupakan alat untuk mengukur kemampuan perusahaan dalam menerima pendapatan atau keuntungan dalam satu periode (Petchsakulwong \& Jansakul, 2018).

Kinerja keuangan mengukur bagaimana perusahaan menggunakan sumber daya yang dimiliki (dalam bisnis utama untuk menghasilkan pengembalian). Kinerja keuangan berdampak 
pada kesehatan perusahaan dan juga dapat digunakan untuk memutuskan tetap eksis dalam dunia usaha. Kinerja marjinal yang lebih baik adalah bahwa perusahaan dapat meningkatkan efektivitas dan efisiensi sumber daya manajemen perusahaan. Perhitungan yang baik dan perekrutan biaya harian dapat berdampak positif pada pembentukan kekayaan perusahaan serta dapat memberikan kontribusi terhadap pertumbuhan ekonomi (Azad et al., 2018).

Penelitian sebelumnya yang telah dilakukan oleh (Rey-Ares et al., 2021) dengan menggunakan metode data panel dinamis yang terdiri dari 377 perusahaan pengalengan ikan di Spanyol selama periode 2010 - 2018, menemukan bahwa modal kerja tidak memiliki keterkaitan dengan profitabilitas, namun di sisi lain pemberian kredit dalam perdagangan dan pemeliharaan persediaan mempengaruhi profitabiltas perusahaan. Penelitian lain dari (Seissian et al., 2018) menggunakan metode regresi linear berganda pada perusahaan yang terdaftar di NYSE periode 2014-2015, menunjukkan peringkat kredit berpengaruh positif dan signifikan terhadap profitabilitas, serta ukuran perusahaan berpengaruh negatif dan signifikan terhadap profitabilitas. (Sivathaasan et al., 2013) menemukan bahwa struktur modal dan non-debt tax shield berpengaruh positif dan signifikan terhadap profitabilitas, sedangkan modal kerja dan ukuran perusahaan tidak berpengaruh signifikan terhadap profitabilitas.

Profitabiltas yang lebih tinggi, selain dapat memungkinkan perusahaan untuk bertahan dan mendatangkan keuntungan di lingkungan bisnis, juga penting untuk evolusi ekonomi berkelanjutan (Işık, 2017). Profitabiltas perusahaan dipengaruhi oleh banyak faktor dan ketika menganalisis profitabilitas, setiap perusahaan harus mempertimbangkan laporan keuangan yang dinyatakan ke dalam posisi keuangan perusahaan, laporan laba rugi dan laporan arus kas. Rasio profitabilitas merupakan faktor utama yang berada pada posisi keuangan karena memuat aset perusahaan, utang dan ekuitas (Mihaela \& Claudia, 2017). Berdasarkan data yang dipublikasi oleh Bursa Efek Indonesia, khususnya perusahaan pertambangan Batubara, terdapat data yang menunjukkan bahwa return on asset, working capital turnover dan total asset turnover perusahaan mengalami fluktuasi selama periode 2017-2019. Bahkan working capital turnover di beberapa perusahaan Batubara memiliki angka yang cukup rendah jika dibandingkan dengan perusahaan Batubara lainnya dalam penelitian ini. Oleh sebab itu, penelitian ini akan mencoba menganalisis relasi faktor-faktor yang mempengaruhi profitabilitas perusahaan sub sektor pertambangan Batubara yang terdaftar di Bursa Efek Indonesia periode 2017-2019. 


\section{TINJAUAN PUSTAKA}

\section{Working Capital Turnover}

Working Capital Turnover adalah rasio untuk mengukur hubungan antara dana yang digunakan dalam membiayai operasi perusahaan dan pendapatan yang dihasilkan perusahaan untuk melanjutkan operasi dan menghasilkan keuntungan. Manajemen modal kerja pertama kali diteliti oleh Nadiri pada tahun 1969. Di antara item modal kerja, kas merupakan aset terpenting yang menjadi kriteria perusahaan dalam memenuhi kewajibannya. Sebaliknya, kas yang menganggur tidak menambah nilai bagi perusahaan. Oleh karena itu, perusahaan perlu menjaga cadangan kas agar pergerakan kas dapat memberikan arus kas yang positif (Jamalinesari \& Soheili, 2015). Jadi, tingkat optimal dari cadangan kas yang dimiliki merupakan elemen penting yang memungkinkan perusahaan untuk meningkatkan bisnisnya (Gill \& Shah, 2012).

Secara umum, konsep modal kerja berarti investasi dalam aset lancar seperti uang tunai, sekuritas, piutang dagang dan persediaan (Çelik et al., 2016). Banyak bisnis yang mengalami kesulitan keuangan, bahkan bangkrut secara tragis karena kesalahan perhitungan kebutuhan modal kerja atau sumber keuangan yang tidak tepat untuk membiayai kebutuhan modal kerja. Dengan demikian, dalam mengelola modal kerja yang efisien sangat diperlukan untuk menjaga keberlangsungan hidup perusahaan, serta pengelolan aset dan kewajibannya (Jamalinesari \& Soheili, 2015).

\section{Total Asset Turnover}

Total Asset Turnover merupakan rasio yang digunakan untuk mengukur bagaimana seluruh aset yang dimiliki oleh suatu perusahaan dioperasikan untuk mendukung penjualan perusahaan (Sitanggang, 2013). Rasio ini menggambarkan kapasitas aset suatu perusahaan untuk menghasilkan total penjualan bersih (Widodo, 2018). Selain itu, rasio ini juga untuk mengukur kemampuan perusahaan secara efisien, dan biasanya digunakan oleh pihak ketiga untuk mengevaluasi operasional bisnis. Secara ideal, perusahaan dengan total asset turnover yang tinggi dapat mengoperasikan lebih sedikit aset daripada perusahaan pesaing yang kurang efisien.

\section{Return on Asset}

Salah satu dasar dalam menilai kondisi suatu perusahaan adalah profitabilitas yang dimilikinya. Profitabilitas merupakan kemampuan perusahana untuk mendapatkan keuntungan 
dalam periode tertentu (Hery, 2017). Alat ukur yang digunakan dalam penelitian ini adalah return on asset. Return on Asset (ROA) merupakan rasio profitabilitas yang memberikan informasi terkait banyaknya keuntungan yang dapat diperoleh perusahaan dari aset yang dimilikinya.

\section{Penelitian Terdahulu}

Beberapa penelitian seperti (Burja, 2011) menunjukkan adanya dampak positif yang kuat sehubungan dengan efisiensi persediaan, tingkat utang, leverage dan efisiensi modal terhadap profitabilitas. (Jasmani, 2019) dengan menggunakan metode regresi linear berganda menemukan bahwa rasio lancar berpengaruh signifikan terhadap return on asset dan perputaran modal kerja juga berpengaruh signifikan terhadap return on asset.

Hasil penelitian lain yang dilakukan oleh (Daryanto \& Rachmanto, 2017) dengan menggunakan metode regresi linear berganda berdasarkan data laporan keuangan PT.Merck Tbk periode 2009-2013 yang diperoleh langsung dari responden menunjukkan bahwa secara parsial perputaran piutang dan perputaran modal kerja tidak berpengaruh signifikan terhadap profitabilitas perusahaan.

Selain itu, dengan mengaplikasikan metode regresi linear berganda pada perusahaan Industri Konsumsi periode 2016-2018, (Nurlaela et al., 2019) menemukan bahwa secara parsial debt to equity ratio, current ratio dan total asset turnover berpengaruh secara signifikan terhadap kinerja keuangan perusahaan yang diukur dengan menggunakan return on asset.

\section{METODE}

Data yang digunakan dalam penelitian ini diperoleh dari laporan keuangan perusahaan sub sektor pertambangan Batubara yang terdaftar di Bursa Efek Indonesia. Data-data tersebut adalah working capital turnover, total asset turnover dan return on asset selama tiga tahun, yaitu dari tahun 2017 sampai tahun 2019. Penelitian dilakukan selama periode ini karena 10 sampel dari perusahaan yang dipilih menyediakan data yang cukup lengkap.

Working capital turnover adalah formula yang menghitung seberapa efisien perusahaan menggunakan modal kerja untuk menghasilkan penjualan. Total asset turnover adalah rasio untuk mengukur kemampuan organisasi atau perusahaan untuk menghasilkan penjualan secara efisien, dan biasanya digunakan oleh pihak ketiga untuk mengevaluasi operasi bisnis. Return on asset 
adalah rasio profitabilitas yang memberikan informasi terkait banyaknya keuntungan yang dapat dihasilkan perusahaan dari penggunaan asetnya.

Pertama-tama, dengan menggunakan model kuadratik, kami memeriksa apakah suku non linear yang terbentuk antara working capital turnover dan total asset turnover cukup berpengaruh signifikan terhadap return on asset. Selanjutnya, jika hasil analisis menunjukkan bahwa suku non linear antar variabel independen tidak cukup berpengaruh signifikan, maka suku non linear pada model kuadratik dapat dieliminasi, sehingga model kuadratik berubah menjadi model regresi linear berganda.

Persamaan regresi linear berganda dituliskan sebagai berikut:

$$
R O A=\beta_{0}+\beta_{1} W C T+\beta_{2} T A T O+\varepsilon,
$$

dengan $R O A$ adalah return on asset, $\beta_{0}$ adalah konstanta, $\beta_{1}$ dan $\beta_{2}$ masing-masing adalah koefisien regresi, WCT adalah working capital turnover, TATO adalah total asset turnover dan $\varepsilon$ adalah error (residu).

\section{HASIL DAN PEMBAHASAN}

\section{Hasil}

\section{Sumber Data}

Sumber data perusahaan pertambangan diperoleh dari laporan keuangan perusahaan yang telah dipublikasikan oleh Bursa Efek Indonesia dari tahun 2017 sampai 2019 dengan jumlah data sebanyak 30 data yang terdiri dari 10 sampel perusahaan. Namun sebagian besar data yang diperoleh adalah data mentah (berupa neraca keuangan dan laporan laba rugi) yang dilaporkan tiap akhir bulan Desember dalam satu tahun. Sehingga, untuk dapat melakukan analisis, kami melakukan beberapa perhitungan untuk mendapatkan data yang diinginkan, yaitu data working capital turnover (WCT), total asset turnover (TATO) dan return on asset (ROA). Berikut disajikan ketiga data di atas dalam bentuk grafik perubahan data riil. 

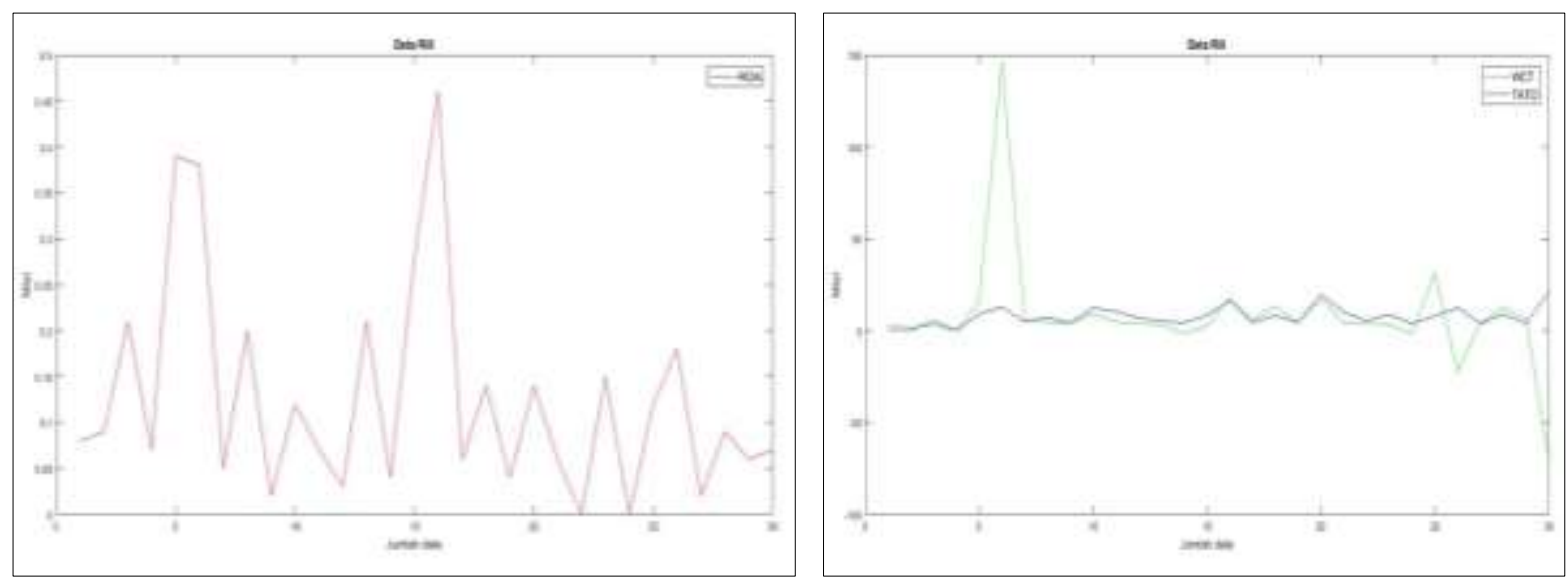

Gambar 1. Perubahan data riil ROA, WCT dan TATO tahun 2017-2019

\section{Regresi Linear Sederhana}

Working capital turnover (WCT) memberi informasi tentang pemanfaatan modal kerja dalam bentuk penjualan per modal kerja dan merupakan salah satu hal yang penting untuk menganalisis kinerja perusahaan (Warrad, 2013). Pengaruh antara WCT terhadap ROA seperti penelitian yang telah dilakukan oleh (Arshad \& Gondal, 2013) pada sektor semen di Bursa Efek Karachi selama periode 2004-2010, menemukan bahwa terdapat pengaruh negatif dan signifikan antara modal kerja terhadap profitabilitas perusahaan tersebut.

Tabel 1. Uji parsial untuk variabel WCT

\begin{tabular}{|c|c|c|c|c|c|}
\hline \multirow[b]{2}{*}{1} & & $\begin{array}{c}\text { Unstandardized } \\
B \\
\end{array}$ & $\begin{array}{c}\text { Standardized } \\
\text { Coefficients }\end{array}$ & & Sig. \\
\hline & $\begin{array}{l}\text { Model } \\
\text { (Constant) }\end{array}$ & 0,112 & Beta & $\begin{array}{l}\mathrm{t} \\
5,599\end{array}$ & 0,000 \\
\hline & WCT & 0,002 & 0,478 & 2,880 & 0,008 \\
\hline
\end{tabular}

a. Dependent Variable: Return On Asset

Berdasarkan Tabel 1 terlihat bahwa working capital turnover berpengaruh signifikan terhadap return on asset dengan nilai signifikansi kurang dari 0,05. 


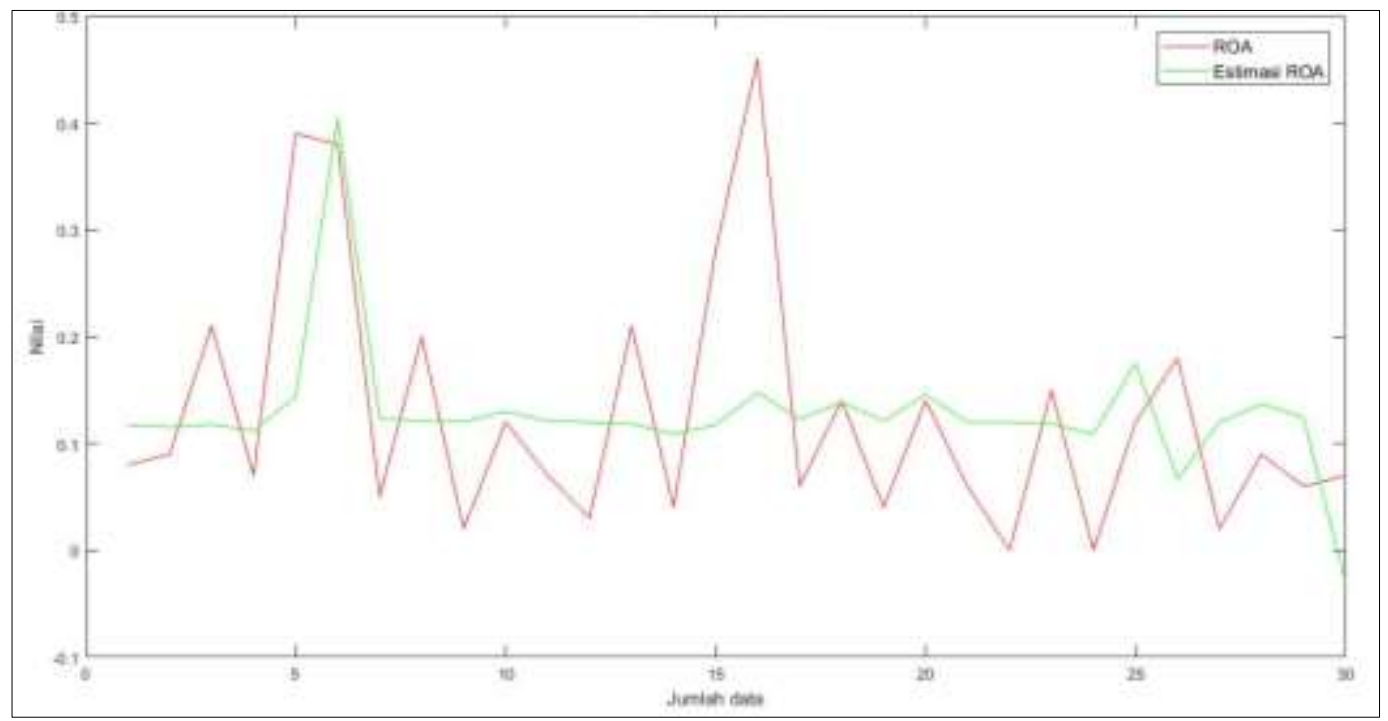

Gambar 2. Dinamika perubahan WCT terhadap ROA

Total asset turnover (TATO) atau perputaran aktiva yang dihitung dengan membagi nilai total pendapatan penjualan perusahaan dengan nilai total asetnya yang meliputi aset fisik, persediaan, dan piutang. Terdapat hubungan positif antara profitabilitas manufaktur dan total aset tetap, karena kedua variabel tersebut membutuhkan persentase aset tetap yang tinggi untuk mengubah bahan mentah menjadi barang jadi (Patin et al., 2020). Selain itu, pertumbuhan aset tetap yang masif seharusnya mengarah pada peningkatan laba selama pemanfaatan total aset untuk meningkatkan produksi dan penjualan (Kantudu, 2008).

Tabel 2. Uji parsial untuk variabel TATO

\begin{tabular}{|c|c|c|c|c|c|}
\hline \multirow[b]{3}{*}{1} & \multirow[b]{2}{*}{ Model } & $\begin{array}{c}\text { Unstandardized } \\
B \\
\end{array}$ & $\begin{array}{c}\text { Standardized } \\
\text { Coefficients }\end{array}$ & \multirow[b]{2}{*}{$\mathrm{t}$} & \multirow{2}{*}{ Sig. } \\
\hline & & & Beta & & \\
\hline & (Constant) & 0,054 & & 1,498 & 0,145 \\
\hline & TATO & 0,010 & 0,422 & 2,466 & 0,020 \\
\hline
\end{tabular}

a. Dependent Variable: Return On Asset

Berdasarkan Tabel 2 terlihat bahwa total asset turnover berpengaruh signifikan terhadap return on asset dengan nilai signifikansi kurang dari 0,05 . 


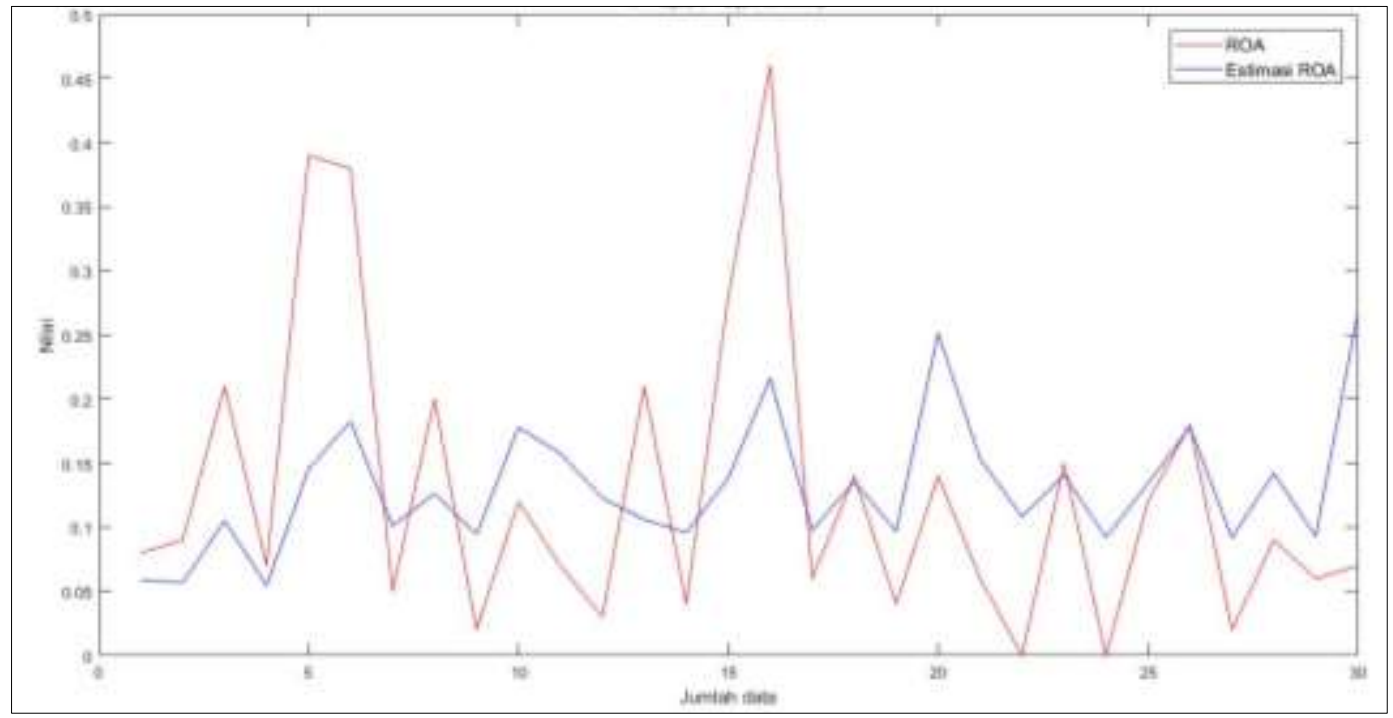

Gambar 3. Dinamika perubahan TATO terhadap ROA

\section{Pemilihan Model}

Persamaan model kuadratik yang digunakan dituliskan sebagai barikut:

$$
R O A=\beta_{00}+\beta_{11} W C T+\beta_{22} \text { TATO }+\beta_{12} \text { WCTxTATO }
$$

dengan $R O A$ adalah return on asset, $\beta_{00}$ adalah konstanta $\beta_{11}, \beta_{22}$ dan $\beta_{12}$ masing-masing adalah koefisien regresi, WCT adalah working capital turnover, dan TATO adalah total asset turnover.

Tabel 3. Nilai koefisien pada model kuadratik

\begin{tabular}{lccccc}
\hline & $R^{2}$ & $\beta_{00}$ & $\beta_{11}$ & $\beta_{22}$ & $\beta_{12}$ \\
\hline ROA & 0,239 & 0,039 & & & \\
WCT & & & 0,001 & & \\
TATO & & & & 0,010 & \\
WCT x TATO & & & & & 0,00006395 \\
\hline
\end{tabular}

Semua hasil perhitungan dihitung dengan menggunakan aplikasi SPSS. Dalam statistik, $R^{2}$ adalah model estimasi yang menafsirkan variabel dependen, yaitu sejauh mana variabel independen mempengaruhi variabel dependen. Dalam model kuadratik ini, variabel independen mempengaruhi variabel dependen sebesar 23,9\%. Berdasarkan Tabel 3, nilai koefisien $\beta_{12}=$ 0,00006395 sangat kecil (mendekati nol) sehingga suku non linear dapat dieliminasi karena tidak 
mempengaruhi variabel dependen secara signifikan. Setelah suku non linear pada Persamaan (2) dieliminasi, maka persamaan tersebut berubah menjadi sebuah persamaan linear.

\section{Hasil Perhitungan Regresi Linear Berganda}

Tabel 4. Regresi linear berganda

\begin{tabular}{lcccc}
\hline & $R^{2}$ & $\beta_{0}$ & $\beta_{1}$ & $\beta_{2}$ \\
\hline ROA & 0,405 & 0,039 & & \\
WCT & & & 0,002 & \\
TATO & & & & 0,010 \\
\hline
\end{tabular}

Dari Tabel 4 dapat dilihat bahwa nilai koefisien $W C T$ sebesar 0,002, yang artinya working capital turnover berpengaruh searah terhadap return on asset. Jika nilai koefisien variabel working capital turnover ditingkatkan sebesar satu satuan, maka return on asset akan meningkat sebesar 0,002 dengan asumsi bahwa nilai koefisien TATO adalah tetap. Kemudian untuk nilai koefisien TATO sebesar 0,010, yang artinya total asset turnover berpengaruh searah terhadap return on asset. Jika nilai koefisien variabel total asset turnover ditingkatkan sebesar satu satuan, maka return on asset akan meningkat sebesar 0,010 dengan asumsi bahwa nilai koefisien $W C T$ adalah tetap.

Pada Tabel 4 juga ditunjukkan bahwa koefisien determinasi dengan $R^{2}$ bernilai 0,405 atau 40,5\% lebih besar dibandingkan dengan nilai $R^{2}$ pada Tabel 3 sebesar 0,239 atau 23,9\%. Dalam kasus ini, kita dapat mengatakan bahwa penggunaan model linear lebih baik dibandingkan dengan model nonlinear. Nilai koefisien determinasi tersebut berarti return on asset dipengaruhi oleh working capital turnover dan total asset turnover sebesar 40,5\%. Sedangkan sisanya sebesar 59,5\% dipengaruhi oleh variabel lain yang tidak diteliti dalam penelitian ini.

Tabel 5. Uji Simultan (Uji F)

\begin{tabular}{llcccll}
\multicolumn{8}{c}{ ANOVA $^{\mathrm{a}}$} \\
\hline & Model & Sum of Squares & df & Mean Square & F & Sig. \\
\hline 1 & Regression & 0,164 & 2 & 0,082 & 9.200 & $0,001^{\mathrm{b}}$ \\
& Residual & 0,240 & 27 & 0.009 & & \\
& Total & 0,404 & 29 & & & \\
\hline
\end{tabular}

a. Dependent Variable: Return On Asset

b. Predictors: (Constant), TATO $\left(X_{1}\right), W C T\left(X_{2}\right)$ 
Berdasarkan Tabel 5 terlihat bahwa secara simultan working capital turnover dan total asset turnover berpengaruh signifikan terhadap return on asset. Hal ini ditunjukkan dengan nilai signifikansi yang kurang dari 0,05 .

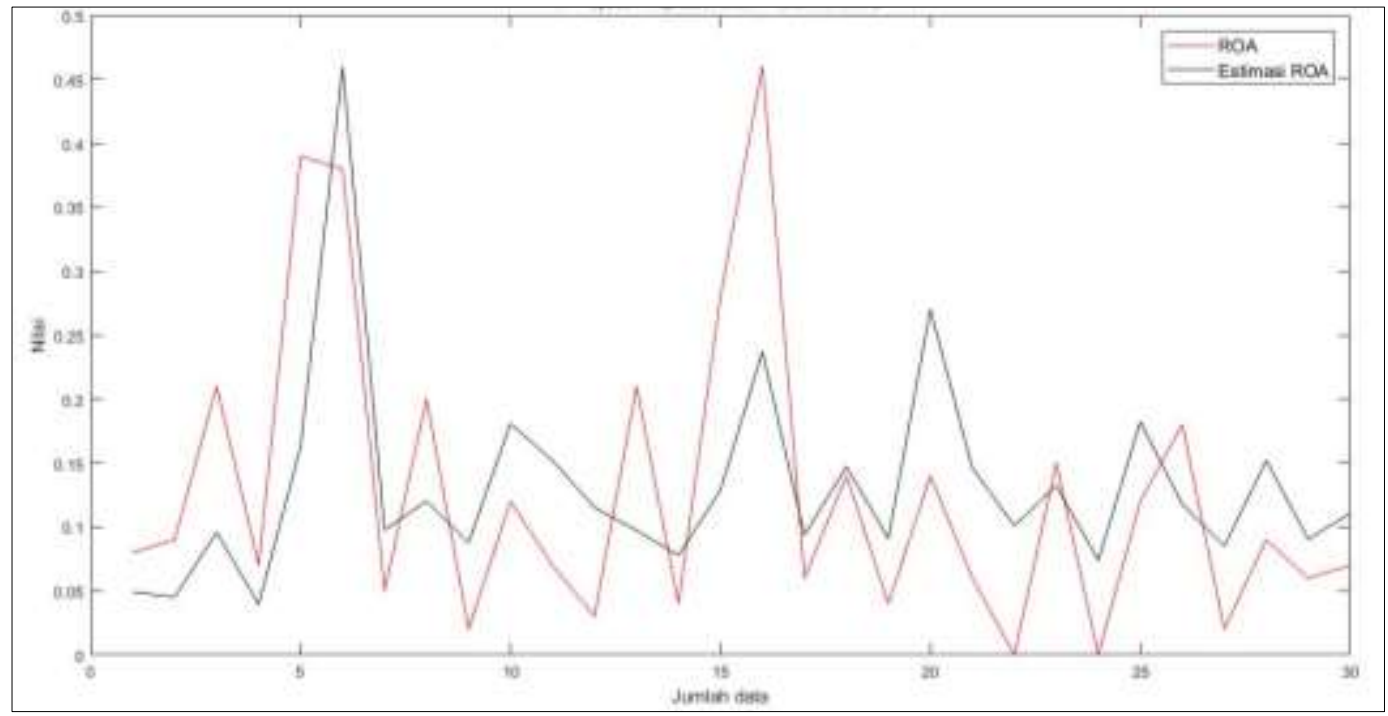

Gambar 4. Dinamika perubahan WCT dan TATO terhadap ROA

\section{Perhitungan Error}

Setiap perhitungan dalam teori regresi selalu memiliki error atau residu. Error merupakan total jumlah dari hasil pengurangan antara nilai sesungguhnya dengan nilai estimasi (dugaan) hasil perhitungan. Pada kasus ini, error adalah total selisih antara ROA dengan hasil perhitungan regresi untuk masing-masing variabel bebas baik secara parsial maupun simultan.

Tabel 6. Error atau residu

\begin{tabular}{clcl}
\hline No. & Variabel Bebas & Persamaan Regresi & Error $(\varepsilon)$ \\
\hline 1. & WCT & $0,112+0,002 X_{1}$ & 2,40712 \\
2. & TATO & $0,054+0,01 X_{2}$ & 2,4827 \\
3. & WCT dan TATO & $0,039+0,002 X_{1}+0,01 X_{2}$ & 2,24766 \\
\hline
\end{tabular}

Tabel 6 menyajikan perbandingan error antara ketiga model regresi dalam menggambarkan dinamika perubahan nilai ROA. Secara parsial, variabel bebas WCT dan TATO memiliki error masing-masing sebesar 2,4071 dan 2,4827. Sedangkan secara simultan, variabel WCT dan TATO memiliki error paling kecil, yaitu sebesar 2,24766. Dengan demikian, dalam kasus ini dapat dikatakan bahwa model regresi linear berganda merupakan model terbaik dalam menggambarkan dinamika perubahan nilai ROA. 


\section{Pembahasan}

Setiap tindakan, aktivitas, fungsi atau proses dalam sebuah perusahaan tentunya akan mempengaruhi profitabiltas perusahaan, baik positif atau negatif. Teknologi informasi (Mithas et al., 2012; Stoneman \& Kwon, 19996), tata kelola perusahaan (Joh, 2003; Rose, 2016), struktur kepemilikan (Gedajlovic \& Shapiro, 2002), modal kerja (Enqvist et al., 2014; Sharma \& Kumar, 2011) dan struktur modal (Gill et al., 2011) adalah sebagai beberapa penentu kekonvergenan profitabilitas perusahaan. Misalnya, profitabilitas perusahaan pertambangan Batubara yang menjadi objek dalam penelitian ini (lihat Gambar 1). Berdasarkan data, return on asset (ROA) pertambangan Batubara periode 2017-2019 mengalami fluktuasi.

Efisiensi perputaran modal kerja sangat penting untuk perusahaan manufaktur seperti perusahaan pertambangan Batubara, dimana sebagian besar asetnya terdiri dari aset lancar yang secara langsung mempengaruhi profitabilitas perusahaan. Pentingnya efisiensi pengelolaan modal kerja tidak dapat dipungkiri karena modal kerja dikenal sebagai kekuatan atau pemberi kehidupan untuk setiap unit ekonomi dan pengelolaannya menjadi bagian penting dari manajemen perusahaan. Setiap organisasi atau perusahaan yang berorientasi pada laba atau tidak, terlepas dari ukuran dan sifat bisnis, tentunya selalu membutuhkan modal kerja yang diperlukan untuk menjalankan organisasi atau perusahaan.

Setiap perusahaan selalu membutuhkan modal kerja karena modal kerja sangat dibutuhkan untuk menjalankan kegiatan operasional perusahaan (Keown et al., 2013). Working capital turnover pada perusahaan pertambangan Batubara menunjukkan pengaruh yang signifikan terhadap ROA. Terlihat pada Tabel 1, nilai working capital turnover menunjukkan nilai 0,008 yang berada di bawah nilai probabilitas 0,05 . Ini berarti bahwa tingkat penjualan yang tinggi pada beberapa perusahaan pertambangan Barubara mampu meningkatkan jumlah keuntungan yang dapat diperoleh. Hal ini juga mengindikasikan bahwa modal kerja berputar lebih cepat sehingga modal dengan cepat dapat kembali ke dalam kas perusahaan. Keuntungan yang meningkat akan mampu menarik minat pemodal untuk melakukan investasi pada sebuah perusahaan. Hasil yang diperoleh dalam penelitian ini sejalan dengan (Satriya \& Lestari, 2014), yang menunjukkan bahwa perputaran modal kerja berpengaruh signifikan terhadap profitabilitas.

Kemudian, hasil analisis terkait total asset turnover dalam penelitian ini menunjukkan nilai signifikansi sebesar 0,020 yang kurang dari nilai probabilitas, yaitu sebesar 0,05 (lihat Tabel 2). 
Dengan demikian, perusahaan mampu mengelola manajemen keuangan secara efektif meskipun terjadi fluktuasi, khususnya pengelolaan perputaran aset atau aktiva yang dimilikinya. Semakin tinggi nilai total asset turnover berarti semakin baik perusahaan dalam mengelola asetnya. Jika kinerja keuangan perusahaan dikelola dengan baik, maka perusahaan akan dapat mengoptimalkan penggunaan aset dalam penjualan yang berdampak pada peningkatan keuntungan perusahaan. Hasil penelitian ini sejalan dengan (Irman et al., 2020) yang menyatakan bahwa total asset turnover berpengaruh positif dan signifikan terhadap profitabilitas. Namun, pihak perusahaan harus lebih hati-hati dan disiplin dalam hal peminjaman, pengumpulan dan pembelanjaan terhadap aset yang dimilikinya agar dapat memberikan keuntungan yang berkelanjutan bagi perusahaan dan pemegang saham.

\section{SIMPULAN}

Pada penelitian ini ditemukan bahwa secara parsial working capital turnover dan total asset turnover berpengaruh positif dan signifikan terhadap return on asset. Selain itu, secara simultan working capital turnover dan total asset turnover berpengaruh signifikan terhadap return on asset. Telah kita ketahui bersama bahwa profitabilitas yang tinggi tidak hanya memungkinkan perusahaan untuk bertahan dan berhasil dalam dunia bisnis yang berisiko, tetapi juga penting untuk pertumbuhan ekonomi berkelanjutan. Sehingga pihak perusahaan harus lebih hati-hati dan disiplin dalam hal peminjaman, pengumpulan dan pembelanjaan terhadap aset yang dimilikinya agar dapat memberikan keuntungan yang berkelanjutan bagi perusahaan dan pemegang saham. Saran untuk topik penelitian selanjutnya adalah peneliti dapat melakukan penelitian terkait hal ini dengan menambah jumlah variabel independen dan jumlah sampel penelitian, serta periode penelitian dengan rentang lebih panjang.

\section{DAFTAR PUSTAKA}

Afza, T., \& Nasir, M. S. (2007). Working Capital Management Practices of Firms: Empirical Evidence from Pakistan. 9th South Asian Management Forum (SAMF), 334-343.

Arshad, Z., \& Gondal, M. Y. (2013). Impact of Working Capital Management on Profitability a Case of the Pakistan Cement Industry. Interdisciplinary Journal of Contemporary Research in Business, 5(2), 384-390.

Azad, A. M. S., Raza, A., \& Zaidi, S. S. Z. (2018). Empirical Relationship between Operational Efficiency and Profitability (Evidence from Pakistan Exploration Sector). Journal of Accounting, Business and Finance Research, 2(1), 7-11. https://doi.org/10.20448/2002.21.7.11

Bijańska, J., \& Wodarski, K. (2014). Risk Management in the Planning of Development Projects 
in the Industrial Enterprises. Metalurgija, 53(2), 276-278.

Burja, C. (2011). Factors Influencing the Companies' Profitability. Annales Universitatis Apulensis Series Oeconomica, 215-224. https://doi.org/10.29302/oeconomica.2011.13.2.3

Çelik, R., Bilen, B., \& Bilen, Ö. (2016). The Impacts of Changes in Macro-Economic Data on Net Working Capital: The Case of Turkey's Industrial Sector. Procedia Economics and Finance, 38, 122-134. https://doi.org/10.1016/s2212-5671(16)30184-8

Daryanto, W. M., \& Rachmanto, F. (2017). The Effect of Working Capital Turnover and Receivable Turnover on Profitability: Case Study on PT. Merck Tbk. International Journal of Business Studies, 1(2), 60-65. https://doi.org/10.32924/ijbs.v1i2.20

Enqvist, J., Graham, M., \& Nikkinen, J. (2014). The Impact of Working Capital Management on Firm Profitability in Different Business Cycles: Evidence from Finland. Research in International Business and Finance, 32, 36-49. https://doi.org/10.2139/ssrn.1794802

Gedajlovic, E., \& Shapiro, D. M. (2002). Ownership Structure and Firm Profitability in Japan. Academy of Management Journal, 45(2), 565-575.

Gill, A., Biger, N., \& Mathur, N. (2011). The Effect of Capital Structure on Profitability: Evidence from the United States. International Journal of Management, 28(4), 3-15.

Gill, A., \& Shah, C. (2012). Determinants of Corporate Cash Holdings: Evidence from Canada. International Journal of Economics and Finance, 4(1), 70-79. https://doi.org/10.5539/ijef.v4n1p70

Hery. (2017). Kajian Riset Akuntansi: Mengulas Berbagai Hasil Penelitian Terkini dalam Bidang Akuntansi dan Keuangan. Jakarta: PT Grasindo.

Hofman, M., Spalek, S., \& Grela, G. (2017). Shedding New Light on Project Portfolio Risk Management. Sustainability, 9, 1-18. https://doi.org/10.3390/su9101798

Irman, M., Purwati, A. A., \& Juliyanti. (2020). Analysis On The Influence Of Current Ratio, Debt to Equity Ratio and Total Asset Turnover Toward Return On Assets On The Otomotive and Component Company That Has Been Registered In Indonesia Stock Exchange Within 20112017. International Journal of Economics Development Research (IJEDR), 1(1), 36-44. https://doi.org/10.37385/ijedr.v1i1.26

Işık, Ö. (2017). Determinants of Profitability: Evidence from Real Sector Firms Listed in Borsa Istanbul. Business and Economics Research Journal, 4(8), 689-698. https://doi.org/10.20409/berj.2017.76

Jamalinesari, S., \& Soheili, H. (2015). The Relationship between the Efficiency of Working Capital Management Companies and Corporate Rule in Tehran Stock Exchange. Procedia Social and Behavioral Sciences, 205, 499-504. https://doi.org/10.1016/j.sbspro.2015.09.052

Jasmani. (2019). The Effect of Liquidity and Working Capital Turnover on Profitability at PT. Sumber Cipta Multiniaga, South Jakarta. Pinisi Discretion Review, 3(1), 29-38.

Joh, S. W. (2003). Corporate Governance and Firm Profitability: Evidence from Korea before the Economic Crisis. Journal of Financial Economics, 68(2), 287-322.

Jonek-Kowalska, I. (2019). Consolidation as a Risk Management Method in the Lifecycle of a Mining Company: A Novel Methodological Approach and Evidence from the Coal Industry in Poland. Resources Policy, 60, 169-177. https://doi.org/10.1016/j.resourpol.2018.12.014

Kantudu, A. S. (2008). Effect of Profitability and Total Assets on the Funded Status of Pension Assets of Quoted Firms in Nigeria. https://papers.ssrn.com/sol3/papers.cfm?abstract_id=1104845

Keown, A. J., Martin, J. D., Petty, J. W., \& Scott, D. F. (2013). Financial Management: Principles 
and Applications, 10 th Edition. England: Pearson Education Limited.

Korski, J., Tobor-Osadnik, K., \& Wyganowska, M. (2016). Reasons of Problems of the Polish Hard Coal Mining in Connection with Restructuring Changes in the Period 1988-2014. Resources Policy, 48, 25-31. https://doi.org/10.1016/j.resourpol.2016.02.005

Matyjaszek, M., Wodarski, K., Krzemien, A., Garcia-Miranda, C. E., \& Sanchez, A. S. (2018). Coking Coal Mining Investment: Boosting European Union's Raw Materials Initiative. Resources Policy, 57, 88-97. https://doi.org/10.1016/j.resourpol.2018.01.012

Mihaela, H., \& Claudia, O. (2017). Does Capital Structure Influence Company Profitability? Studies in Business and Economics, 12(3), 50-62. https://doi.org/10.1515/sbe-2017-0036

Mithas, S., Tafti, A., Bardhan, I., \& Goh, J. M. (2012). Information Technology and Firm Profitability: Mechanisms and Empircal Evidence. MIS Quarterly, 36(1), 205-224. https://misq.org/information-technology-and-firm-profitability-mechanisms-and-empiricalevidence.html

Nurlaela, S., Mursito, B., Kustiyah, E., Istiqomah, I., \& Hartono, S. (2019). Asset Turnover, Capital Structure and Financial Performance Consumption Industry Company in Indonesia Stock Exchange. International Journal of Economics and Financial Issues, 9(3), 297-301. https://doi.org/10.32479/ijefi.8185

Patin, J.-C., Rahman, M., \& Mustafa, M. (2020). Impact of Total Asset Turnover Ratios on Equity Returns: Dynamic Panel Data Analyses. Journal of Accounting, Business and Management (JABM), 27(1), 19-29. https://doi.org/10.31966/jabminternational.v27i2.689

Petchsakulwong, P., \& Jansakul, N. (2018). Board of Directors and Profitability Ratio of Thai nonlife Insurers. Kasetsart Journal of Social Sciences, 39(1), 122-128. https://doi.org/10.1016/j.kjss.2017.11.005

Qamara, T., Wulandari, A., Sukoco, A., \& Suyono, J. (2020). The Influence of Current Ratio, Debt to Equity Ratio, And Total Asset Turnover Ratio on Profitability of Transportation Companies Listed On the Indonesia Stock Exchange 2014-2018. IJIEEB(International Journal of Integrated Education, Engineering and Business), 3(2), 81-93. https://doi.org/10.29138/ijieeb.v3i2.1169

Rey-Ares, L., Fernández-López, S., \& Rodeiro-Pazos, D. (2021). Impact of Working Capital Management on Profitability for Spanish Fish Canning Companies. Marine Policy, 130, 104583. https://doi.org/10.1016/j.marpol.2021.104583

Rose, C. (2016). Firm Performance and Comply or Explain Disclosure in Corporate Governance. European Management Journal, 34(3), 202-222. https://doi.org/10.1016/j.emj.2016.03.003

Satriya, I. M. D., \& Lestari, P. V. (2014). Pengaruh Perputaran Modal Kerja Terhadap Profitabilitas Perusahaan. E-Jurnal Manajemen, 3(7), 1927-1942.

Seissian, L. A., Gharios, R. T., \& Awad, A. B. (2018). Structural and Market-Related Factors Impacting Profitability: A Cross Sectional Study of Listed Companies. Arab Economic and Business Journal, 13(2), 125-133. https://doi.org/10.1016/j.aebj.2018.09.001

Sharma, A. K., \& Kumar, S. (2011). Effect of Working Capital Management on Firm Profitability Empirical Evidence from India. Global Business Review, 12(1), 159-173. https://doi.org/10.1177/097215091001200110

Sitanggang, J. (2013). Manajemen Keuangan Perusahaan Lanjutan. Jakarta: Mitra Wacana Media.

Sivathaasan, N., Tharanika, R., Sinthuja, M., \& Hanitha, V. (2013). Factors Determining Profitability: A Study of Selected Manufacturing Companies Listed on Colombo Stock Exchange in Sri Lanka. European Journal of Business and Management, 5(27), 99-107. 
Snigaroff, R., \& Wroblewski, D. (2021). Earnings and 1 Liquidity Factors. The Quarterly Review of Economics and Finance, 80, 508-523. https://doi.org/10.1016/j.qref.2021.03.011

Stefan, I. O. B. (2015). Study on the Profitability of Romanian Companies Listed on Bucharest Stock Exchange. Procedia Economics and Finance, 30(15), 797-807. https://doi.org/10.1016/s2212-5671(15)01329-5

Stoneman, P., \& Kwon, M. J. (19996). Technology Adoption and Firm Profitability. The Economic Journal, 106, 952-962.

Warrad, L. (2013). The Impact of Working Capital Turnover on Jordanian Chemical Industries' Profitability. American Journal of Economics and Business Administration, 5(3), 116-119. https://doi.org/10.3844/ajebasp.2013.116.119

Widodo, A. (2018). Analisis Pengaruh Current Ratio (CR), Total Asset Turnover (TATO) dan Debt to Asset Ratio (DAR) terhadap Return on Asset (ROA), serta Dampaknya terhadap Nilai Perusahaan (Studi terhadap Perusahaan Jasa Penunjang Migas pada Bursa Efek Indonesia Periode Tah. Jurnal Ilmiah Manajemen Forkamma, 1(2), 87-112. 